\section{Commentary: The case for a comprehensive clinical, basic, and translational research strategy to understand, prevent, detect, and treat cerebrovascular injury in Fontan patients}

\author{
David Kalfa, MD, PhD
}

In this issue of the Journal, the Australian and New-Zealand Fontan Registry Research group compares long-term rates of cerebrovascular injury, thrombosis, bleeding, bone mineral density, and quality of life in Fontan patients receiving warfarin and those receiving aspirin. ${ }^{1}$ Their take-home messages are (1) asymptomatic cerebrovascular injury is a frequent occurrence in Fontan patients, including stroke $(39 \%)$, microhemorrhage $(96 \%)$, and white matter injury $(86 \%)$; (2) warfarin does not seem to protect against the risk of cerebrovascular injury when compared with aspirin; and (3) warfarin is associated with a greater risk of bleeding and reduced bone mineral density. Based on these findings, the authors favor aspirin for primary long-term thromboprophylaxis after Fontan surgery.

This series is one of the largest on this topic reported to date, with neuroimaging done specifically for this study, and the Australian and New-Zealand Fontan Registry is a well-established and reliable data source with a strong track record of significant and useful publications. Nevertheless, the study has some limitations. These limitations are mainly related to the study's cross-sectional design, with a low participation rate of $17 \%-25 \%$, the small number of participants per treatment group, and the geographical distribution of patients receiving each treatment.

\footnotetext{
From the Section of Pediatric and Congenital Cardiac Surgery, Division of Cardiac, Thoracic and Vascular Surgery, Columbia University Medical Center, New York Presbyterian-Morgan Stanley Children's Hospital, New York, NY.

Disclosures: The author reported no conflicts of interest.

The Journal policy requires editors and reviewers to disclose conflicts of interest and to decline handling or reviewing manuscripts for which they may have a conflict of interest. The editors and reviewers of this article have no conflicts of interest.

Received for publication Jan 11, 2021; revisions received Jan 11, 2021; accepted for publication Jan 12, 2021; available ahead of print Jan 20, 2021.

Address for reprints: David Kalfa, MD, PhD, Pediatric Cardiac Surgery, Columbia University Medical Center, New York Presbyterian-Morgan Stanley Children's Hospital, 3959 Broadway, New York, NY 10032 (E-mail: dk2757@cumc. columbia.edu).

J Thorac Cardiovasc Surg 2021;162:1229-30

$0022-5223 / \$ 36.00$

Copyright (C) 2021 by The American Association for Thoracic Surgery

https://doi.org/10.1016/j.jtcvs.2021.01.045
}

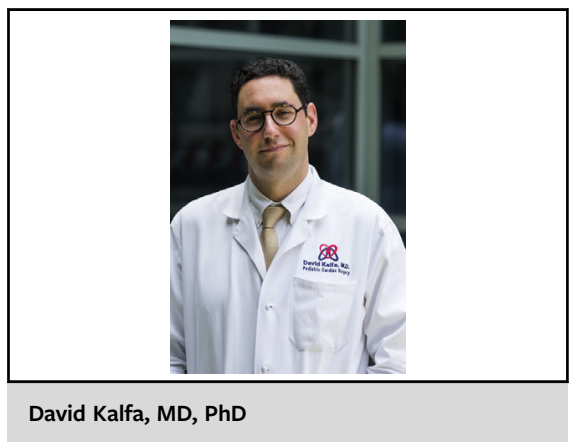

\author{
CENTRAL MESSAGE \\ Cerebrovascular injury is \\ frequent in Fontan patients \\ regardless of anticoagulation \\ therapy. This gap needs to be \\ filled through a comprehensive \\ clinical, basic, and translational \\ research strategy.
}

Despite its limitations, this study is eye-opening for our community. We are not good at detecting and preventing cerebrovascular complications and thrombohemorrhagic complications in Fontan patients. This major gap can be and should be addressed in different ways: (1) understand the dysregulation of the coagulation (and inflammation) pathways related to the Fontan physiology and in the single ventricle population in general; (2) determine when these cerebrovascular injuries occur and identify the patient-dependent and proceduredependent risk factors for such complications; (3) implement a systematic neurologic imaging policy to detect and treat asymptomatic thromboembolic complications in this population to reduce the long-term impact in term of neurodevelopmental outcomes; (4) conduct a large-scale randomized trial to get a final answer on the benefits of aspirin versus warfarin in Fontan patients; (5) investigate the efficacy and safety of other nonconventional anticoagulation therapies, such as P2YI2 inhibitors, in the Fontan population.

Despite all this knowledge and studies, we may not get a black and white answer as to which anticoagulant is best for these Fontan patients, and a case-by-case determination of the best course of treatment for each patient may be needed. In this event, a computational-based patient-specific prediction model my be needed to identify the best anticoagulation option for each patient based on specific risk factors, 
the type of Fontan operation performed, the presence and size of the fenestration, the material used for the actual Fontan connection, noncardiac comorbidities (eg, risk of extracardiac and extracerebral bleeding, risk of bone mineral density decrease on warfarin), and patient preference.

More than half a century after the first Fontan operation was performed, it is time now to get these answers and know what we should offer to our Fontan patients. They deserve it.

\section{Reference}

1. Attard C, Monagle PT, d'Udekem Y, Mackay MT, Briody J, Cordina R, et al. Long-term outcomes of warfarin versus aspirin after Fontan surgery. J Thorac Cardiovasc Surg. 2021;162:1218-28.e3.
See Article page 1218.

\section{Commentary: Less is more}

\author{
Constantine D. Mavroudis, MD, MSc, MTR, and \\ Katsuhide Maeda, MD
}

While exceedingly common in modern vernacular, the term "less is more" is ascribed to renowned architect Ludwig Mies Van der Rohe. His artistic approach sought to simplify architecture to its most basic elements. By removing ornate details and inefficient uses of space and material, he not only defined an entire architectural movement, but his efficient use of steel and glass also helped to define the modern skyscraper, which persists long after his death.

Those practitioners who advocate a "less-is-more" approach to anticoagulation following the Fontan procedure were given further evidence in this issue of the Journal. Attard and colleagues ${ }^{1}$ demonstrated that, among those patients who were older than 13 years and had been maintained on either warfarin or aspirin therapy for thromboprophylaxis for a duration of 5 years or longer, those treated with aspirin had the same incidence of stroke but had significantly lower incidence of bleeding complications compared with the warfarin group. This study builds on previous studies that have demonstrated similar incidence of thrombotic complications between patients with Fontan circulation treated with aspirin compared with warfarin ${ }^{2,3}$ but is novel in its focus on patients further

From the Division of Cardiothoracic Surgery, Department of Surgery, Children's Hospital of Philadelphia, Philadelphia, Pa.

Disclosures: The authors reported no conflicts of interest.

The Journal policy requires editors and reviewers to disclose conflicts of interest and to decline handling or reviewing manuscripts for which they may have a conflict of interest. The editors and reviewers of this article have no conflicts of interest.

Received for publication Jan 8, 2021; revisions received Jan 8, 2021; accepted for publication Jan 8, 2021; available ahead of print Jan 19, 2021

Address for reprints: Katsuhide Maeda, MD, Division of Cardiothoracic Surgery, Department of Surgery, Children's Hospital of Philadelphia, Philadelphia, PA 19104 (E-mail: maedak@chop.edu).

J Thorac Cardiovasc Surg 2021;162:1230-1

$0022-5223 / \$ 36.00$

Copyright (c) 2021 by The American Association for Thoracic Surgery

https://doi.org/10.1016/j.jtcvs.2021.01.021

\section{Check for updates}

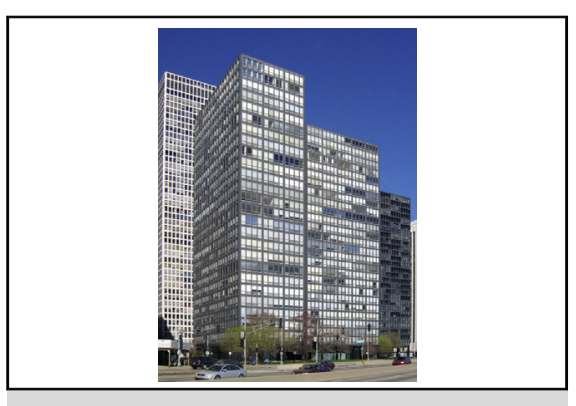

N Lake Shore Drive apt bdg designed by Ludwig Mies van der Rohe. (c) Jeremy Atherton, 2006.

CENTRAL MESSAGE
Among Fontans treated with
aspirin or warfarin, this study
found increased bleeding in the
warfarin group, but no throm-
bosis difference. Further studies
are needed to optimize Fontan
anticoagulation.

removed from their Fontan operation (greater than 11 years). This focus on a more adolescent patient population is important, as adolescent patients present unique challenges. Of particular interest in this study is the authors' assessment of bone density, where they demonstrate significant bone density loss among patients treated with warfarin. It is particularly poignant to see such clinical changes in children who already have so many additional comorbidities.

Thrombotic complications in Fontan circulation are unfortunately common, and their etiology is multifactorial. Even though this study demonstrated equivalent thrombotic complications between warfarin and aspirin in patients with Fontan 